
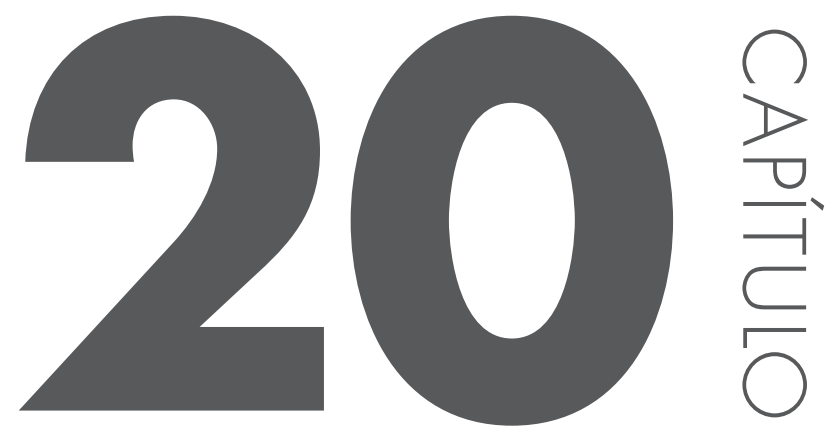

\title{
EXPERIMENTOS DE BAIXO CUSTO NO ENSINO dE FÍsICA NA EDUCAC̣̃̃o
}

Barbosa, Aline Pereira do Nascimento ${ }^{1}$; Andreata, Mauro Antonio '

' Universidade Federal de Goiás, Departamento de Física - Regional Catalão

*email: alinepnas @ hotmail.com 
Resumo: A necessidade de escutar os estudantes, verificar suas motivações, seus conhecimentos prévios e sua relação com o saber é um dos caminhos para melhorar o Ensino de Física. A metodologia pedagógica escolhida se apoia na utilização de kits experimentais de baixo custo, e na busca de estratégias de ensino alternativas, procuramos possíveis explicações e soluções para alguns problemas e dificuldades que permeiam o Ensino de Física. Neste trabalho, relatamos como foi a utilização de experimentos nas aulas de Ciências (Física) pelos alunos do Ensino Fundamental, de uma escola da rede pública em Inhumas-Go. Introduzimos a prática experimental com uso de kits confeccionados a partir de material de baixo custo, e elaboramos o material didático, com conceitos físicos, exemplos do cotidiano e roteiro do experimento, para auxiliar os alunos durante a aula. Discutimos ainda os resultados parciais que obtivemos até agora.

\section{Palavras-chave: Conhecimentos prévios; Ensino de Física; Prática experimental}




\section{Introdução}

Atualmente existe a necessidade de escutar os estudantes, verificar suas motivações, seus conhecimentos prévios e sua relação com o saber. Segundo Carvalho Junior (2011), o ensino de ciências tem apresentado, nas últimas décadas, um notável progresso com relação à estas necessidades. Na literatura, encontram-se várias estratégias de ensino, havendo um aumento nas tentativas de construção de diferentes formas de ensinar.

A disciplina de Física deveria ser desenvolvida não apenas de forma teórica, mas apoiada em conjunto com aulas práticas que introduzam e aprimorem os conceitos trabalhados em sala de aula. Ao apresentá-la apenas de forma teórica, o aprendizado é 
dificultado pelo desinteresse dos alunos que veem a Física como uma disciplina abstrata, desvinculada da realidade e restrita à resolução matemática de problemas.

Ainda de acordo com Carvalho Junior (2011), o ensino de Física deve permitir que os alunos, através de atividades propostas durante as aulas, tenham acesso a conceitos, leis, modelos e teorias que expliquem satisfatoriamente o mundo em que vivem. $O$ professor ao realizar seu trabalho de forma crítica, auxilia o aluno a construir uma mentalidade também crítica, questionadora, transgressora. Conforme o autor, podemos separar o ensino de Física em conceitual e matematizado.

A linha conceitual trabalha a compreensão de fenômenos físicos através da discussão, do debate e do enfrentamento de posições. Nesta linha, acreditamos que a utilização de fórmulas matemáticas pode auxiliar a quantificação dos fenômenos, mas que só deve ser utilizada a partir do momento em que os alunos compreenderem os conceitos envolvidos. Já a concepção matematizada enfatiza as equações que permeiam a Física, priorizando a memorização de leis e fórmulas para posterior aplicação na resolução de problemas, tornando a Física um conjunto de conceitos prontos que devem ser transmitidos aos alunos. Um ensino de Física matematizado faz do professor o retentor das verdades científicas e o aluno é concebido como mero receptor do conhecimento físico estabelecido, o que produz uma falsa ideia do que realmente seja Física. Assim, resta ao aluno obedecer aos desígnios das fórmulas, calcular o que foi pedido e apresentar resultados desconectados da sua realidade.

Devemos romper com o pensamento onde o professor apenas faz uso do quadro e sua fala, e o aluno, nessa realidade, apenas ouve, copia e memoriza. Evitar aulas cansativas, desestimulantes e monótonas com a utilização de experimentos construídos com materiais de baixo custo, na busca de uma melhor aprendizagem, despertar o interesse dos alunos, levando-os a participar das atividades, em aulas mais motivadoras, onde o aluno deverá ser levado a pensar, descobrir e perguntar, na busca de respostas, dentre outras coisas. A Física é interessante quando estudada através da compreensão dos fenômenos naturais ou não, mostrando suas belezas, com uma aprendizagem eficaz, divertida e agradável. O contato com fenômenos físicos vai fornecendo elementos para que o aluno elabore representações sobre os diversos conceitos físicos e as relações entre eles. Essa construção se inicia na infância e vai ocorrendo ao longo da vida.

Aulas são mais fascinantes quando teoria e prática caminham juntas. Se o professor só recorre à teoria, o aluno acaba achando o conteúdo e até mesmo toda a disciplina não muito atraente, não tendo motivação e gosto pela ciência. É possivel despertar o interesse dos alunos por Física, através de aulas mais interessantes aos alunos, e para isso há vários livros e sites que possuem uma vasta lista de experimentos que estudantes e professores podem fazer na sala de aula. $O$ aluno aprende melhor quando consegue relacionar a ciência com $\circ$ meio que o cerca. Entender o ambiente em que vive, através de conteúdos estudados na escola, faz com que a disciplina deixe de ser aprendida apenas com o método de decorar.

Os alunos devem deixar de ser meros receptores de informação e começar a serem investigadores, exercitando o pensamento científico, para se tornarem cidadãos mais atentos ao mundo e até mesmo tendo a possibilidade de melhorar o ambiente em que vivem. 


\section{Justificativa Teórica}

"A escola deve facilitar a construção de conhecimentos, a transformação da informação, procedente dos diferentes saberes disciplinares, em conhecimento próprio" (HERNÁNDEZ; VENTURA; 1998). O aluno deve ser um formador de opinião, então cabe à escola oferecer o conhecimento necessário para que se torne um crítico construtivo, um bom profissional e bom cidadão.

Aulas de Física costumam ser expositivas e tradicionais, os professores não fazem uso dos vários recursos didáticos disponíveis para torná-las atrativas. Os alunos são condicionados a ver a Física como aplicação de fórmulas, não desenvolvendo habilidades de interpretação, análise teórica da situação-problema e tampouco experimentação de fenômenos físicos.

O objetivo das aulas, consideradas tradicionais, é transmitir o que supostamente deve ser ensinado, considerar o aluno um caderno em branco, e nele se colocar as informações necessárias. Importa apenas a transmissão de maior variedade e a quantidade de noções, conceitos e equações matemáticas, deixando de lado a formação do pensamento reflexivo.

O aluno necessita adquirir conhecimento, habilidades e hábitos, buscar a superação de crendices, superstições e preconceitos. A Física utiliza a mesma linguagem que a Matemática, com uma realização exagerada de resolução de exercícios, através de cálculos, o aluno, sem saber o verdadeiro motivo de se resolver tantos cálculos, acaba relacionando a Física e a Matemática como disciplinas semelhantes. A distância entre a realidade vivida pelos alunos e a apresentada em sala de aula precisa diminuir, o conhecimento contextualizado é o recurso que a escola tem para retirar o aluno da condição de espectador passivo. $O$ cotidiano e as relações estabelecidas com o ambiente físico e social devem dar significado a qualquer conteúdo curricular, e fazer a ponte entre o que se aprende na escola e o que se faz, vive e observa no dia a dia.

Contextualizar é uma estratégia para a construção de significações. A contextualização do ensino deve incorporar vivências concretas e diversificadas, é uma postura que deve estar frente ao ensino o tempo todo, o aluno deve ser seduzido, o professor deve instigar a curiosidade dos alunos. A sabedoria dos alunos deve se apoiar na investigação criativa e vigorosa de tudo o que é visto, ouvido, lido e tocado (TAKIMOTO, 2009).

Diante de tais ideias, surgiram alguns questionamentos:

- Ao considerar que o primeiro contato entre os alunos e a Física ocorre no fim do Ensino Fundamental, será que, ao se depararem com um problema de Física, saberão identificar a situação-problema?

- Será que conseguirão levantar hipóteses e escolher algum caminho para a solução?

- Será que serão capazes de analisar os resultados de experimentos físicos realizados e verificar se há coerência com a realidade em que vivem?

Sendo assim, o principal objetivo deste trabalho é verificar o contato de alunos do nono ano do Ensino Fundamental com a Física, realizar experimentos físicos, introduzir a prática experimental e averiguar se ocorrerá diminuição a uma suposta aversão a disciplina, sentida pela maioria dos alunos. Estimular os professores da escola a ensinar Física unindo teoria e 
prática. Despertar o senso crítico-científico e o gosto pela ciência nos alunos do Ensino Fundamental. Avaliar de forma sistemática os resultados da aprendizagem com a aplicação de atividades experimentais. Propiciar a aprendizagem por meio da pesquisa.

Esperamos que com estes experimentos haja melhor rendimento escolar dos alunos e aumente a sua compreensão de fenômenos físicos.

\section{Metodologia}

É uma pesquisa qualitativa a qual permite uma maior liberdade de ação e de aprendizagem dos participantes. A pesquisa foi iniciada junho de 2014 e terá seu término em junho de 2015, ocorre com alunos do Ensino Fundamental da Escola Municipal Alessandro Miguel, em Inhumas - Go, para os quais foram apresentados experimentos físicos contextualizados, fabricados com materiais de baixo custo.. Após verificados os conteúdos ministrados no nono ano da escola, iniciamos a confecção de kits com material de baixo custo.

Com os kits confeccionados, foi desenvolvido o material didático a ser usado em cada aula. Constam de explicação da teoria com exemplos práticos e do cotidiano dos alunos e roteiro do experimento realizado durante a aula ministrada.

A análise do processo de ensino-aprendizagem ocorreu por meio de observações da reação dos alunos durante os experimentos, onde verificamos as diferentes interpretações do fenômeno abordado, a fixação dos conceitos estudados e se as ideias errôneas préconcebidas foram eliminadas. Todo o material obtido foi utilizado especificamente para os propósitos da pesquisa.

As questões a seguir, dentre outras, nortearam o caminho da pesquisa: $A$ aula experimental foi eficiente em transmitir o assunto abordado? Houve motivação dos alunos com essa técnica? Os kits experimentais funcionaram de forma eficaz para a compreensão dos fenômenos estudados?

A análise dos dados seguiu a proposta de Minayo (1994) de interpretação qualitativa de dados. Podemos destacar dois pressupostos desse método de análise: o primeiro diz respeito à ideia de que não há consenso e nem ponto de chegada a processo de produção do conhecimento; o segundo se refere ao fato de que a ciência se constrói numa relação dinâmica entre a razão daqueles que a praticam e a experiência que surge na realidade concreta.

Minayo (1994) apresenta os seguintes passos para a operacionalização de sua proposta:

a) Ordenação dos dados: nesse momento, faz-se um mapeamento de todos os dados obtidos no trabalho de campo. Aqui estão envolvidos, por exemplo, transcrição das falas, releitura do material, organização dos relatos e dos dados da observação participante.

b) Classificação dos dados: nessa fase é importante termos em mente que o dado não existe por si só. Ele é construído a partir de um questionamento que fazemos sobre ele, com base numa fundamentação teórica. 
c) Análise final: nesse momento, procuramos estabelecer articulações entre os dados e os referenciais teóricos da pesquisa, respondendo às questões da pesquisa com base em seus objetivos. Assim, promovemos relações entre o concreto e o abstrato, o geral e o particular, a teoria e a prática.

Confeccionamos os kits e desenvolvemos o material didático com explicações da teoria, exemplos práticos e do cotidiano e o roteiro dos experimentos. A figura 1 apresenta uma versão alternativa do dispositivo que possibilitou Otto Von Guerick (1602-1686, físico alemão, notabilizado pelo estudo do vácuo e da eletrostática) formar vácuo e demonstrar os efeitos da pressão entre duas superfícies. Conhecido como as Placas de Magdeburg, em que a pressão externa força um hemisfério tão fortemente contra o outro.

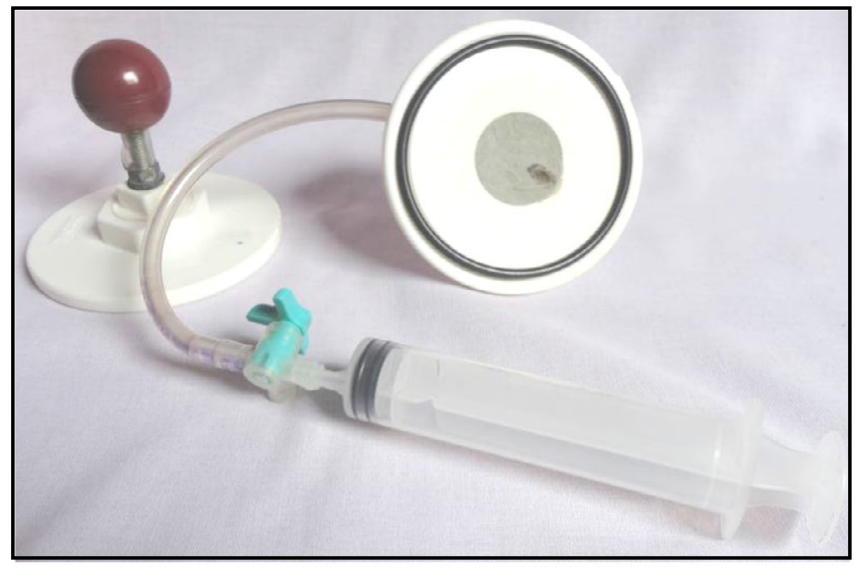

Figura 1 - Placas de Magdeburg: a pressão externa força um hemisfério tão fortemente contra o outro.

Montamos este kit durante uma oficina realizada no XVII SNEF. São usadas duas placas de acrílico e uma seringa para remover o ar entre elas. Em cada placa há um sulco circular onde se encaixa o anel de borracha para delimitar um pequeno volume de ar entre as placas. Em uma das placas há um furo próximo ao centro onde passa um tubo de plástico que é conectado a uma seringa. Puxamos o êmbolo da seringa e, em seguida, fecharmos o tubo de plástico com uma presilha. Depois de parte do ar entre as placas ter sido removida com a seringa, a pressão do ar entre as placas fica menor que a pressão externa (pressãa atmosférica).

Como a pressão atmosférica é da ordem de $10^{5} \mathrm{~N} / \mathrm{m}^{2}$, com uma pequena diferença de pressão dessa ordem a força necessária para separar as duas placas é muito grande. Aumentando-se a área (com o anel de maior diâmetro), essa força será proporcionalmente maior. Então, um estudante ao tentar separar as duas placas puxando-as pelas alças não conseguirá ou terá dificuldade para separar as duas placas.

O ebulidor de Franklin, figura 2, é um brinquedo encontrado em feiras de artesanato ou loja de produtos importados, com os mais diversos formatos e cores. É um instrumento constituído de um bulbo de vidro totalmente vedado, separado em duas regiões conectadas por um tubo e, em seu interior, um líquido colorido muito volátil, podendo ser álcool, 
clorofórmio, éter, dentre outros. Com ele verificamos a movimentação do líquido ao variar a sua temperatura.

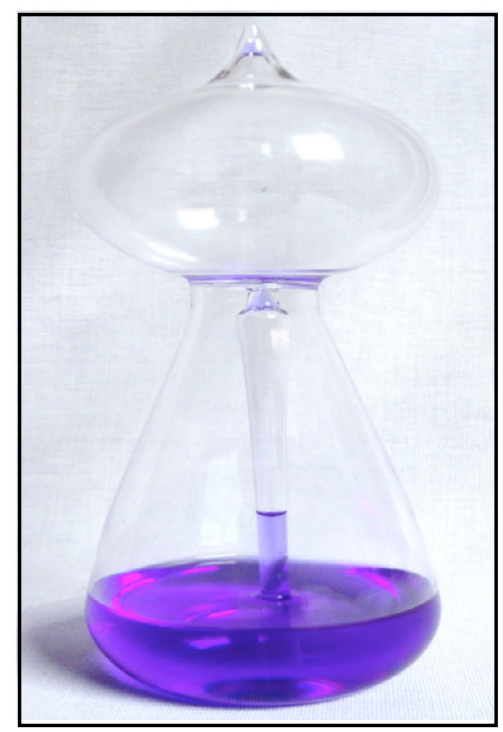

Figura 2 - Ebulidor de Franklin - ao variar a temperatura ocorre um aumento de pressão deslocando do líquido para cima.

O estudante deve segurar a parte inferior do ebulidor de Franklin, fazendo com que o líquido em seu interior (álcool) se desloque para a parte superior. Ao transferir calor da mão do estudante para o líquido, o que acelera o processo de evaporação de um líquido muito volátil e leva a um aumento na pressão. Esse aumento de pressão faz com que o líquido se desloque para cima. Quando colocamos a mão em contato com o bulbo inferior, há uma troca de calor entre ela e o vidro, porém, isso só acontece caso exista uma diferença de temperatura entre os dois corpos, o gás contido nesta parte do recipiente se aquece rapidamente e, por esse motivo, a energia cinética de suas moléculas aumenta consideravelmente. Desse modo, aumenta a pressão que o gás exerce sobre o líquido. Devido a este aumento de pressão e ao fato de haver somente gás no bulbo superior, o líquido sobe pelo tubo de vidro que conecta os dois tubos até jorrar no bulbo superior.

\section{Resulfados e discussão}

A pesquisa foi iniciada com a investigação dos conteúdos ministrados no nono ano na disciplina de Ciências - Física, para que a partir desta informação pudéssemos iniciar a confecção dos kits experimentais. Os conteúdos são: grandezas físicas e unidades; energia e suas modalidades; fontes e matrizes energéticas; força, trabalho e potência; forças produzindo movimentos; leis de Newton; gravitação; calor e suas manifestações; ondulatória; luz; sistemas ópticos; eletrização; associação de resistores; distribuição e utilização da energia elétrica. 
No ensino público dificilmente encontramos professores de Ciências do nono ano com formação em Física, a maioria tem formação em Biologia, e algumas vezes em Química, como é o caso da escola visitada. E esse fato é relevante, pois é clara a dificuldade do professor a frente de uma área do conhecimento, na ocasião a Física, e deixar de lado aulas tradicionais e implementar aulas práticas no cotidiano de sua turma. Mas também não é algo impossível, pois com kits experimentais confeccionados com material de baixo custo, podemos contornar esta dificuldade e suprir a necessidade de motivar os alunos, conduzir, assim, o conhecimento físico de forma mais eficaz.

No ambiente escolar encontramos vários tipos de alunos, e durante a aula não podemos agradar a todos, mas devemos cativar pelo menos a maioria. Ao observarmos os alunos, de uma turma com nove estudantes, durante a aula experimental, verificamos que a maior parte dos alunos demostrou entusiasmo durante toda a aula. Responderam as perguntas sobre o tema abordado, leram o material didático, assimilaram os exemplos contidos no texto com situações vividas por eles e realizaram o experimento com certa empolgação. A participação foi satisfatória. Outra parcela, pequena, mas significante, não se interessou em utilizar os kits experimentais, porém fizeram uso do material didático e questionamentos sobre os temas abordados, participando, com isso, da aula prática.

No primeiro momento, realizamos o experimento das Placas de Magdeburg. Fizemos uma leitura do material didático, e durante esta leitura um aluno perguntou o que seria o vácuo. O professor da turma, que também estava presente e participando, se dispôs a responder com as seguintes palavras: "vácuo é quando não se tem a resistência do ar, quando não tem ar, principalmente". Falamos então de alguns exemplos, como o homem na lua, que necessitou de roupa apropriada para a ocasião, e também sobre alimentos embalados a vácuo para retirar o ar presente dentro da embalagem e diminuir a propagação de fungos e bactérias.

Outro exemplo discutido foi a lata de óleo ou azeite, o porquê de se fazer dois furos na lata, e também tomar refresco com canudinho, já que se colocarmos um dentro do refresco e outro fora, não conseguimos sugar o líquido do refresco. A partir disso fizemos uma explicação de como funcionava o kit experimental, e também sobre alguns conceitos físicos como pressão atmosférica (fora das placas), pressão (dentro das placas), força, dentre outros.

Os alunos realizaram o experimento e observamos que eles constataram os conceitos físicos discutidos antes de sua realização. E um aluno perguntou se entra as placas gerava suor, e falamos que ao retirarmos o ar, estamos retirando também à umidade entre as placas, e com isso, não temos "suor" entre elas. Separamos as placas e ele constatou que estava seco. Lembraram também do filme Missão Impossível, onde o ator consegue escalar um prédio com equipamentos que utilizam os princípios e conceitos discutidos na aula.

Em um segundo momento, realizamos o experimento do Ebulidor de Franklin, e questionamos os alunos sobre seu funcionamento. Eles discutiram sobre aquecer $o$ kit ou as mãos que estariam em contato com ele, e constataram que para não danificar o kit, já que seu material é vidro, era necessário apenas aquecer as mãos para facilitar o deslocamento do liquido. 
Os kits experimentais funcionaram de forma satisfatória, os fenômenos físicos abordados eram evidentes com o uso dos kits. Os alunos, ao serem questionados, conseguiram relacionar tais fenômenos com situações vividas por eles, contextualizando, mesmo se baseando muito no senso comum, após serem corrigidos com a apresentação de conceitos físicos, conseguiram assimilar o conhecimento físico e passar a fazer uso do senso crítico-científico. $O$ uso do material didático foi satisfatório, o texto conseguiu auxiliar os alunos, os exemplos acompanhados de figuras relacionadas a situações do cotidiano ajudaram a compreensão dos conceitos físicos a serem adquiridos. E como já citamos, o material didático agradou tanto aos alunos que simpatizaram pela aula experimental quanto aos alunos que não tiveram a mesma empolgação.

Diante dos fatos observados, concluímos que introduzir aulas práticas é um quesito positivo para melhorar a aprendizagem, os alunos, em sua maioria, se sentiram motivados e estimulados a terem gosto pela ciência, a serem ativos na aula, fazendo perguntas e respondendo o que lhes era perguntado, auxiliando os colegas nas respostas às perguntas e na execução do experimento. Com isso, esperamos que consigam construir o conhecimento a partir do senso crítico-científico, tornando-se bons profissionais e bons cidadãos. 


\title{
Low cost experiments in Physics teaching in basic education
}

\begin{abstract}
The need to listen to students, checking their motivations, their previous knowledge and its relationship with knowledge is one of the ways to improve the Teaching of Physics. The pedagogical methodology chosen is based on the use of low cost experimental kits, and the search for alternative teaching strategies, seek possible explanations and solutions to some problems and difficulties that permeate the Teaching of Physics. In this work, we report as was the use of experiments in Science classes (Physics) by elementary school students in a public school in Inhumas-Go. We introduce experimental practice with use of kits made from both low cost materials, and prepare teaching materials, with physical concepts, examples from everyday life and script of the experiment, to assist students during class. We also discuss partial results we have obtained so far.
\end{abstract}

Keywords: Previous knowledge; Physics Teaching; Experimental practice.

\section{Referências bibliográficas}

CARVALHO JUNIOR, Gabriel Dias de. Aulas de física, do planejamento à avaliação. Livraria da Física. São Paulo: 2011.

HERNÁNDEZ, Fernando; VENTURA, Montserrat. Os projetos de trabalho: uma forma de organizar os conhecimentos escolares. In: A organização do currículo por projetos de trabalho: 0 conhecimento é um caleidoscópio. Artes Médicas. Porto Alegre: 1998.

MINAYO, Maria Cecília de Souza (org), et al. Pesquisa Social: Teoria, método e criatividade. Vozes. Petrópolis, RJ: 1994.

TAKIMOTO, E. História da Física na sala de aula. Livraria da Física. São Paulo: 2009. 